\title{
Insulin Secretion, Insulin Action, and Hepatic Glucose Production in Identical Twins Discordant for Non-Insulin-dependent Diabetes Mellitus
}

\author{
Allan Vaag, * Jan Erik Henriksen, ${ }^{\star}$ Sten Madsbad, ${ }^{*}$ Niels Holm, ${ }^{\mathbb{5}}$ and Henning Beck-Nielsen \\ $*$ Odense University Hospital, Department of Endocrinology and Internal Medicine M, Odense; ${ }^{\ddagger}$ Hvidovre University Hospital, \\ Department of Endocrinology and Internal Medicine, Hvidovre; and ${ }^{\S}$ Department for Genetics, Odense University, Odense, Denmark
}

\begin{abstract}
12 identical twin pairs discordant for non-insulin-dependent diabetes mellitus (NIDDM) were studied for insulin sensitivity (euglycemic insulin clamp, $40 \mathrm{mU} / \mathrm{m}^{2}$ per $\mathrm{min}$ ), hepatic glucose production (HGP, $\left[3-{ }^{3} \mathrm{H}\right]$ glucose infusion), and insulin secretion (oral glucose tolerance test and hyperglycemic [12 mM] clamp, including glucagon administration). Five of the nondiabetic twins had normal and seven had impaired glucose tolerance. 13 matched, healthy subjects without a family history of diabetes were included as control subjects. The NIDDM twins were more obese compared with their non-diabetic co-twins. The nondiabetic twins were insulin resistant and had a delayed insulin and C-peptide response during oral glucose tolerance tests compared with controls. Furthermore, the nondiabetic twins had a decreased first-phase insulin response and a decreased maximal insulin secretion capacity during hyperglycemic clamping and intravenous glucagon administration. Nondiabetic twins and controls had similar rates of HGP. Compared with both nondiabetic twins and controls, the NIDDM twins had an elevated basal rate of HGP, a further decreased insulin sensitivity, and a further impaired insulin secretion pattern as determined by all tests. In conclusion, defects of both in vivo insulin secretion and insulin action are present in non- and possibly prediabetic twins who possess the necessary NIDDM susceptibility genes. However, all defects of both insulin secretion and glucose metabolism are expressed quantitatively more severely in their identical co-twins with overt NIDDM. (J. Clin. Invest. 1995. 95:690-698.) Key words: non-insulin-dependent diabetes mellitus • insulin secretion • insulin resistance $\cdot$ hepatic glucose production • identical twins
\end{abstract}

\section{Introduction}

Development of non-insulin-dependent diabetes mellitus $(\text { NIDDM })^{1}$ is the consequence of a complicated interplay be-

Address correspondence to Dr. Allan Vaag, Odense University Hospital, Department of Endocrinology and Internal Medicine M, Sdr. Boulevard, Odense, Denmark. Phone: 66113333; FAX: 65919653. 1994

Received for publication 31 May 1994 and in revised form 3 October

1. Abbreviations used in this paper: BMI, body mass index; FFM, fatfree mass; HGP, hepatic glucose production; IGTT, impaired glucosetolerant twin; NGTT, normal glucose-tolerant twin; NIDDM, non-insulin-dependent diabetes mellitus; OGTT, oral glucose tolerance test.

J. Clin. Invest.

(C) The American Society for Clinical Investigation, Inc.

0021-9738/95/02/0690/09 \$2.00

Volume 95, February 1995, 690-698 tween impaired insulin secretion, peripheral insulin resistance, and a disproportionately elevated rate of hepatic glucose production (HGP) on one hand (1-3) and the influence of inherited versus environmental factors on those parameters on the other (4-19). The genetic component of the disease is supported from epidemiologic and metabolic studies in genetically predisposed individuals (4-18), and the environmental component is especially evidenced by the strong association between the occurrence of NIDDM and the propagation of the modern western life style (19).

However, there is still no consensus concerning the essential question as to which of, and to what extent, the three major abnormalities of glucose metabolism in NIDDM are primary and perhaps genetically determined and which are secondary to the other abnormalities of glucose and lipid metabolism that follow development of frank NIDDM (20). The aim of this study was to investigate insulin secretion, insulin action, and HGP in a group of identical twin pairs discordant for NIDDM. It was postulated that nondiabetic identical twins with a documented NIDDM co-twin are more likely to expose an (the) underlying primary and perhaps genetically determined defect(s) of glucose metabolism responsible for NIDDM than are first-degree relatives. Furthermore, the concept of studying identical twins discordant for NIDDM would allow not only identification of defects in glucose metabolism in nondiabetic subjects with a presumably $100 \%$ genetic determination for NIDDM, but would also allow identification and quantification of the extent to which secondary (nongenetic) factors associated with overt NIDDM influence insulin secretion and glucose metabolism in NIDDM.

\section{Methods}

Subjects. The identical twins were identified primarily through the Danish Twin Register (21). Questionnaires were sent during the year of 1990 to the twin pairs born between 1918 and 1940 who were recorded in the files as being identical (monozygotic) based on the similarity method (21). Included were twins born in Denmark during the period from 1918 to 1930 and twins born in the Funen county during the period from 1931 to 1940 for which both partners were recorded as being alive. Questionnaires were sent to a total of 1,252 twin subjects ( $=626$ twin pairs). The twins were asked specifically whether they suffered from diabetes and, if they did, their age at diagnosis. All twins were also asked about the presence of hypertension or other relevant diseases. The classification of NIDDM was based primarily on the diagnosis of diabetes after the age of $40 \mathrm{yr}$. A total of 1,064 individuals (twins) answered the questionnaires. Among these individuals, 932 belonged to twin pairs in which both of the twins answered the questionnaires $(=466$ twin pairs). Six twin pairs ( $n=12$ individuals) reported that both twins suffered from diabetes diagnosed after the age of $40 \mathrm{yr}$ (concordant twin pairs), and 20 twin pairs ( $n=40$ individuals) reported that diabetes was diagnosed in only one of the twins after the age of $40 \mathrm{yr}$ (discordant twin pairs). Thus, according to the answers of the questionnaires, the study initially revealed a pairwise concordance rate of only $23 \%$ for 
diabetes diagnosed after the age of $40 \mathrm{yr}$ in this large population of identical twins. Two twin pairs reported diabetes in one of the twins diagnosed before the age of $40 \mathrm{yr}$, and two twin pairs reported diabetes diagnosed in both twins before the age of $40 \mathrm{yr}$. Of the remaining 132 "single"-twin answers, two individuals reported diabetes diagnosed after the age of $40 \mathrm{yr}$.

A further contact was made to the twins belonging to pairs who reported discordance for diabetes diagnosed after the age of $40 \mathrm{yr}$, in order to find out whether these twin pairs were truly identical (monozygotic) and discordant for NIDDM. One of those diabetic twins reported that diabetes had developed shortly after an abdominal operation involving the pancreas, and one reported normal weight and absolute insulin dependence since diabetes was diagnosed at the age of $45 \mathrm{yr}$. Since the diagnosis of "classic NIDDM" could be questioned in both of these individuals, these two discordant twin pairs were excluded from the study. Two other discordant twin pairs did not accept to participate in any studies of glucose metabolism involving blood samples, and two pairs were not asked to participate because of information about serious illness in one or both twins.

The remaining 14 discordant twin pairs, plus two other putative identical twin pairs discordant for NIDDM traced through the outpatient clinic at Odense University Hospital ( $n=32$ individuals), underwent a standardized 75-g oral glucose tolerance test (OGTT), and genetic markers were determined to confirm that the twin pairs were identical (monozygotic). The genetic markers included the following blood, serum, and enzyme types: ABO, MNS, RH, LEAB, HP, GC, PGM-1, ACP-1, GPT, ASD, and GLO. Twins were classified as monozygotic when all types were concordant (22).

1 of the 16 twin pairs was excluded because of the finding of nonidentity (dizygosity) according to the above genetic markers, and 2 twin pairs were excluded because of the finding of frank NIDDM (2-h plasma glucose concentration during OGTT $>11 \mathrm{mM}$ ) in both twins. Furthermore, in one of the twin pairs, diabetes was not confirmed in the twin who initially reported diabetes. Of the remaining 12 discordant and identical twin pairs, 5 of the nondiabetic twins had a normal OGTT (2-h plasma glucose concentration $<7.8 \mathrm{mM}$ ) (NGTT) and 7 had a impaired OGTT (2-h plasma glucose concentration between 7.8 and $10.5 \mathrm{mM}$ ) (IGTT). All of the 12 twin pairs accepted to participate in the studies of glucose metabolism as outlined in the following section. However, one of the twins with an impaired OGTT withdrew his acceptance to participate in the hyperglycemic clamp study after participation in the euglycemic clamp study. Among the 12 identical twin pairs discordant for NIDDM, 6 pairs reported a positive family history of diabetes in first- and/or second-degree relatives other than the affected NIDDM twins.

13 healthy, age- and sex-matched subjects with a normal OGTT and without a family history of diabetes or hypertension were included as a control group. The control group was selected primarily to match the nondiabetic twins (NGTT and IGTTs) according to their average weight. The control subjects were recruited from the same Caucasian background population as the twins and were included consecutively in the study provided they fulfilled the inclusion criteria. One of the controls was a twin, whereas the other 12 controls were not twins. (See Table I for clinical characteristics of identical twin pairs and controls.) Four of the diabetics were treated with diet alone, seven with oral hypoglycemic agents ( five with sulfonylureas, one with metformin, and one with a combination of sulfonylureas and metformin), and one with insulin. This patient had been treated with insulin for only 6 mo prior to the participation in the metabolic studies, and had a duration of diabetes of $9 \mathrm{yr}$ (a body mass index [BMI] of $30.3 \mathrm{~kg} / \mathrm{m}^{2}$ ), and was 62 -yr-old at the time when diabetes was diagnosed. Four of the diabetic patients were treated for hypertension; one with thiazide diuretics, one with loop diuretics, one with combined loop diuretics and potassiumsparing diuretics, and one with combined thiazide diuretics and a $\beta$ adrenergic blocking agent. One of the NGTTs and one of the IGTTs were treated for hypertension with $\beta$-adrenergic blocking agents. Furthermore, one of the IGTTs was treated with nitroglycerin because of ischemic heart disease (angina pectoris, but no previous myocardial infarctions). None of the control subjects received any medication. All medications (including insulin) were withdrawn in the treated twins at least $72 \mathrm{~h}$ prior to studies. Plasma glucose concentrations and resting blood pressures were measured in patients after the withdrawal of treatment (see Table I). Besides diabetes, hypertension, and angina pectoris in one subject, none of the subjects had any clinical evidence of endocrine, cardiac, hepatic, or renal disease. Subjects were not undertaking arduous exercise on a regular basis, and all subjects were instructed to avoid excessive physical exercise at least $2 \mathrm{~d}$ before clamp studies. Studies in the controls, NIDDM, and nondiabetic twins were run in parallel. All studies of glucose metabolism were performed after a 10$\mathrm{h}$ overnight fast, and subjects were requested to have a diet intake of $>150 \mathrm{~g}$ of carbohydrate per day for $3 \mathrm{~d}$ prior to the tests. Informed consent was obtained from all subjects. The protocol was approved by the regional ethical committee, and the procedures were performed according to the principles of the Helsinki Declaration.

Oral glucose tolerance tests. Plasma glucose and insulin concentrations were measured at the following time points during the standardized 75-g OGTTs: $-20,-10,0,5,10,15,20,30,40,50,60,75,90,120$, 150 , and $180 \mathrm{~min}$. Plasma C-peptide concentrations were measured at $-20 \mathrm{~min}$ (fasting) and at $30 \mathrm{~min}$. The $30 \mathrm{~min}$ plasma insulin and Cpeptide concentrations were used as estimates of the initial insulin secretion during OGTTs (23).

Baseline and clamp insulin-stimulated glucose turnover determinations. All studies were started in the morning after a 10-h overnight fast. A polyethylene catheter was inserted into an antecubital vein for infusion of test substances. Another polyethylene catheter was inserted into a contralateral wrist vein for blood sampling. This hand was placed and maintained in a heated Plexiglas box to obtain arterialized venous blood (24). Plasma glucose was normalized in the diabetic patients before each study by an intravenous insulin infusion given over a period of $52 \pm 8$ min $($ mean $\pm S E)$. The mean $\pm \mathrm{SE}$ of the insulin dose given during this period was $9.4 \pm 2.1 \mathrm{IU}$ or $0.17 \pm 0.03 \mathrm{IU} / \mathrm{min}$. The insulin infusion was stopped when the plasma glucose concentration had declined to a mean of $6.4 \pm 0.3 \mathrm{mM}$, and an additional period of $30 \mathrm{~min}$ elapsed while the plasma glucose concentration continued to decline to $4.9 \pm 0.3 \mathrm{mM}$, which was similar to the fasting plasma glucose concentration in the control subjects of $5.4 \pm 0.1 \mathrm{mM}$. This time point marked the initiation of each experiment (time $-120 \mathrm{~min}$ ), when the tracer bolus was given. None of the diabetic patients experienced episodes of either clinical or chemical hypoglycemia during these initial adjustments of the plasma glucose concentrations. This study design was chosen in the NIDDM patients in order to overcome the known compensatory effect of hyperglycemia on the various defects of glucose metabolism in NIDDM (25) and thereby to study glucose metabolism in the NIDDM twins at low plasma glucose and basal insulin concentrations similar to those in the fasting control subjects and nondiabetic twins. Baseline measurements of glucose metabolism were performed during the predefined baseline "steady-state" period from -30 to $0 \mathrm{~min}$ (i.e., $\sim 135$ min after insulin infusion ceased), when tracer equilibrium was anticipated (i.e., constant specific activities) (see Fig. 3). Except for the prior insulin infusion, the controls were studied in the fasting euglycemic state, using a similar protocol with a primed continuous glucose tracer infusion from $-120 \mathrm{~min}$ and a steady-state period from -30 to $0 \mathrm{~min}$ for baseline determinations.

After the -120 - to 0 -min equilibration period for baseline measurements (i.e., at $0 \mathrm{~min}$ ), insulin (Actrapid, Novo-Nordisk, Bagsvaerd, Denmark) was infused for $+180 \mathrm{~min}$ at a constant rate of $40 \mathrm{mU} / \mathrm{m}^{2}$ per min in both NIDDM patients and control subjects. Plasma glucose concentration was maintained constant at euglycemia using a variable glucose infusion ( $180 \mathrm{~g} /$ liter $)(26)$. Plasma glucose concentration was monitored in arterialized blood every 5-10 min, using an automated glucose oxidase method (Glucose Analyzer 2; Beckman Instruments, Fullerton, CA). Measurements of insulin-stimulated glucose turnover rates were performed from +150 to +180 min during clamps (i.e., predefined insulin-stimulated steady-state periods). Plasma concentrations of glucose and insulin were measured every $10 \mathrm{~min}$ during both baseline and insulin-stimulated steady-state periods. 
The glucose clamp studies were combined with a primed $(22 \mu \mathrm{Ci})$, continuous $(0.22 \mu \mathrm{Ci} / \mathrm{min})$ infusion of $\left[3-{ }^{3} \mathrm{H}\right]$ glucose (New England Nuclear, Boston, MA). The radiochemical purity of the tracer was $100 \%$, as determined by HPLC. To ensure achievement of isotope equilibrium, the continuous infusion of $\left[3-{ }^{3} \mathrm{H}\right]$ glucose was initiated at the time point of -120 min and continued throughout the +180 - min period of insulin infusion. Furthermore, to obtain constant specific activity during insulin infusion, tritiated glucose was added to the infused cold glucose $(100 \mu \mathrm{Ci}$ per $500 \mathrm{ml}$ of $18 \%$ glucose $)(27)$. Blood samples were drawn in fluoride-treated tubes every 10 min during both steadystate periods for the determination of plasma glucose and plasma [3${ }^{3} \mathrm{H}$ ] glucose radioactivity. During the rest of the study period, plasma glucose and plasma $\left[3-{ }^{3} \mathrm{H}\right]$ glucose radioactivity were measured every $30 \mathrm{~min}$.

Glucose turnover rates (HGP and total peripheral glucose disposal) were calculated at 10-min intervals during the predefined steady-state periods using Steele's non-steady-state equations (28). Thus, although steady state was clearly obtained for all measurements of tritiated glucose specific activities in all subjects (see Fig. 3), the NIDDM patients were studied during a non-steady-state baseline situation with a spontaneously increasing plasma glucose concentrations (Fig. 3). In the calculations of glucose turnover rates, the distribution volume of glucose was taken as $200 \mathrm{ml}$ per $\mathrm{kg}$ of body weight and the pool fraction as 0.65 (29). Residual HGP during clamp studies was calculated by subtracting the rate of exogenously infused glucose from the rate of appearance of $\left[3-{ }^{3} \mathrm{H}\right]$ glucose.

Glucose turnover rates were expressed as milligrams per kilogram of fat-free mass (FFM) per min and are presented throughout the paper as the mean values calculated over the two 30 -min steady-state periods. Total body fat content (and thus FFM) was measured with the bioimpedance method (30).

Hyperglycemic clamp studies. On a separate day, all study subjects underwent a 150-min hyperglycemic clamp experiment for the determination of pancreatic $\beta$ cell secretory capacity (26). All subjects were studied after a 10-h overnight fast. However, to overcome the influence of fasting hyperglycemia on insulin secretion (31) and to obtain "baseline" plasma glucose levels similar to those in the controls and nondiabetic twins, fasting hyperglycemia was normalized in the NIDDM patients by a prior intravenous insulin infusion that was withdrawn at least $30 \mathrm{~min}$ before the initiation of experiments. A total insulin dose of $10.3 \pm 2.0 \mathrm{IU}$ was given over a period of $59 \pm 14 \mathrm{~min}(=0.23 \pm 0.04 \mathrm{IU} /$ min). Plasma glucose concentrations were similar in NIDDM twins compared with both nondiabetic twins $(5.2 \pm 0.3$ vs $6.0 \pm 0.19 \mathrm{mM}$ [NGTT], $5.6 \pm 0.2 \mathrm{mM}$ [IGTT]) and controls ( $5.2 \pm 0.3$ vs $5.2 \pm 0.1 \mathrm{mM}$, NS) at the initiation of the experiments (time $-2 \mathrm{~min}$ ). Slightly higher fasting plasma glucose concentrations (at time $-2 \mathrm{~min}$ ) were observed in the combined group of nondiabetic twins compared with controls $(6.0 \pm 0.19 \mathrm{mM}$ [NGTT], $5.6 \pm 0.2 \mathrm{mM}$ [IGTT] vs $5.2 \pm 0.1 \mathrm{mM}, P$ $<0.01$ ). The plasma glucose concentration was raised acutely ( -2 to $0 \mathrm{~min}$ ) in all subjects by means of an intravenous bolus glucose infusion of $0.27 \mathrm{~g}$ of glucose per $\mathrm{kg}$ of total body weight; and the plasma glucose concentration was maintained elevated at a constant level of $\sim 12 \mathrm{mM}$ by means of subsequent variable and frequently adjusted intravenous infusion of glucose (180 g/liter) (26). At the 120 -min time point, 1 $\mathrm{mg}$ of glucagon was injected intravenously in order to enhance pancreatic insulin secretion further ("maximal insulin secretion capacity") Blood samples were drawn prior to the glucose infusion (time $-2 \mathrm{~min}$ ) and at the time points $1,3,5,7,9,12,15,30,45,60,75,90,105,110$, $115,120,122,124,126,128,130,135,140$, and $150 \mathrm{~min}$ for the determination of plasma glucose and insulin concentrations.

The first-phase insulin secretory response was defined as the incremental area under the plasma insulin curve during the first $11 \mathrm{~min}$ after the initiation of the 2 -min bolus glucose infusion (i.e., 9 min after the termination of the bolus glucose infusion) (see Fig. 5). The secondphase insulin secretory response was defined as the incremental area under the plasma insulin curve from 9 to $120 \mathrm{~min}$ after the bolus glucose infusion (see Fig. 5), and the maximal capacity insulin secretion represents the incremental area under the plasma insulin curve $30 \mathrm{~min}$ after the intravenous glucagon injection from 120 to $150 \mathrm{~min}$ (see Fig. 5). The areas under curves were all calculated using the trapezoidal method.

Assays. Glucose in plasma was determined using an automated glucose oxidase method. Plasma insulin concentrations were measured using a double-antibody radioimmunological method (Pharmacia Diagnostics AB, Uppsala, Sweden). Cross-reactivity with proinsulin in the assay was $40 \%$. Plasma $C$-peptide concentrations were measured using a two-site, two-step, time-resolved immunofluorometric assay (32). Tritiated glucose activity was measured as described by Hother-Nielsen and Beck-Nielsen (33). $\mathrm{HbA}_{\mathrm{lc}}$ (glycosylated hemoglobin) was measured by HPLC (normal range 5.4-7.4\%). Plasma triglyceride, total cholesterol, HDL cholesterol, LDL cholesterol, and VLDL cholesterol concentrations were determined using commercial kits from Boehinger (Mannheim Germany).

Statistical analysis. Nonparametric statistical methods (Wilcoxon test for paired data, Mann-Whitney test for unpaired data, and Spearmans rho $[R]$ for correlation analysis) were employed in the primary analysis of data. Furthermore, all comparisons of insulin secretion and glucose turnover rates between groups of controls, nondiabetic, and NIDDM twins were tested and corrected for multiple comparisons and for age and BMI as covariates using parametric ANOVA (Statgraphics statistical package, Manugistics Inc., Rockville, MD). $P \leq 0.05$ was considered significant. Data are presented as the mean \pm SEM. The group of nondiabetic twins includes both normal (NGTT) and impaired (IGTT) glucose tolerant twins according to the World Health Organization criterias. In all comparisons made throughout the paper, measurements in the total group of nondiabetic twins $(N=11-12)$ are tested statistically against measurements made in the groups of NIDDM twins (to estimate the contribution of environmental factors on a given parameter) and controls without any family history of diabetes (to identify potential primary or genetic components). However, whenever data are given for the group of nondiabetic twins, the mean values are given separately for both groups (i.e., NGTTs and IGTTs). Furthermore, whenever differences are found between measurements in the group of nondiabetic twins and control subjects, the groups of NGTTs $(n=5)$ and IGTTs $(n=6-7)$ are tested separately toward the group of controls $(n=13)$.

\section{Results}

Clinical and basic biochemical characteristics of subjects. The average duration of diabetes in the group of NIDDM twins was $9 \pm 3 \mathrm{yr}$, with a range from 1 to $32 \mathrm{yr}$. The NIDDM twins were significantly more obese (BMI) than their nondiabetic co-twins and the control subjects (Table I). The absolute weight was also higher in the NIDDM twins compared with their nondiabetic co-twins $(P<0.05)$ and the controls (NS; $P<0.07)$. The waist/hip ratio was higher in both the NIDDM twins and their nondiabetic cotwins compared with the controls without a family history of diabetes. The waist/hip ratio was similar in identical twins with and without NIDDM. However, the group of IGTTs had a significantly elevated waist/hip ratio compared with both NGTTs and controls. The total body fat content or FFM did not differ significantly among the groups. Plasma lipoprotein concentrations were similar in the groups, except for a significantly lower plasma HDL cholesterol concentration in the NIDDM twins compared with the controls. The combined group of nondiabetic twins had a significantly elevated fasting plasma glucose concentration compared with the group of controls (Table I). However, when the two groups of nondiabetic twins (NGTTs and IGTTs) were considered separately, only the NGTT group had a significantly elevated fasting plasma glucose concentration compared with the controls. In addition the group of NGTTs had a significantly elevated plasma glucose concentration $2 \mathrm{~h}$ after the OGTT compared with the controls. 


\begin{tabular}{|c|c|c|c|c|}
\hline & $\begin{array}{l}\text { Twins with } \\
\text { NIDDM }\end{array}$ & $\begin{array}{l}\text { Twins with imparied } \\
\text { glucose tolerance (IGTT) }\end{array}$ & $\begin{array}{l}\text { Twins with normal } \\
\text { glucose tolerance (NGTT) }\end{array}$ & Control subjects \\
\hline$n$ (Females/Males) & $12(5 / 7)$ & $7(3 / 4)$ & $5(2 / 3)$ & $13(6 / 7)$ \\
\hline Age $(\mathrm{yr})$ & $64 \pm 3$ & $67 \pm 4$ & $59 \pm 5$ & $60 \pm 2$ \\
\hline Weight (kg) & $84 \pm 4^{*}$ & $74 \pm 6$ & $77 \pm 5$ & $76 \pm 3$ \\
\hline Height $(\mathrm{cm})$ & $167 \pm 4$ & $164 \pm 5$ & $169 \pm 6$ & $170 \pm 3$ \\
\hline BMI $\left(\mathrm{kg} / \mathrm{m}^{2}\right)$ & $30.1 \pm 1.3^{* \neq}$ & $27.6 \pm 2.0$ & $27.2 \pm 1.5$ & $26.5 \pm 0.8$ \\
\hline Body fat $(\mathrm{kg})$ & $27 \pm 2$ & $25 \pm 3$ & $24 \pm 3$ & $24 \pm 3$ \\
\hline Fat free mass $(\mathrm{kg})$ & $56 \pm 3$ & $49 \pm 4$ & $53 \pm 6$ & $52 \pm 3$ \\
\hline Waist/hip ratio & $1.00 \pm 0.02^{8}$ & $1.04 \pm 0.03^{\text {ह11 }}$ & $0.93 \pm 0.02$ & $0.90 \pm 0.03 *$ \\
\hline Triglycerides (mM) & $1.83 \pm 0.31$ & $1.16 \pm 0.14$ & $1.34 \pm 0.30$ & $1.26 \pm 0.22$ \\
\hline Cholesterol (mM) & $5.5 \pm 0.3$ & $5.3 \pm 0.4$ & $5.6 \pm 0.4$ & $5.9 \pm 0.3$ \\
\hline HDL cholesterol (mM) & $1.05 \pm 0.10^{\ddagger}$ & $1.14 \pm 0.14$ & $1.05 \pm 0.06$ & $1.33 \pm 0.09$ \\
\hline LDL cholestreol (mM) & $4.04 \pm 0.25$ & $3.94 \pm 0.42$ & $4.36 \pm 0.27$ & $3.95 \pm 0.29$ \\
\hline Fasting plasma glucose (mM) & $11.4 \pm 1.1^{89}$ & $5.8 \pm 0.2$ & $6.2 \pm 0.1^{\ddagger}$ & $5.4 \pm 0.2 *$ \\
\hline 2-h OGTT plasma glucose (mM) & $19.5 \pm 1.7^{81}$ & $9.1 \pm 0.5^{8 * *}$ & $6.8 \pm 0.3^{\ddagger}$ & $5.7 \pm 0.3$ \\
\hline $\mathrm{HbA}_{1 \mathrm{c}}(\%)$ & $8.9 \pm 0.5^{81}$ & $6.9 \pm 0.2^{\ddagger}$ & $6.7 \pm 0.3$ & $6.2 \pm 0.2^{*}$ \\
\hline Fasting plasma insulin $(\mu \mathrm{U} / \mathrm{ml})$ & $12.7 \pm 1.6^{1 \neq \ddagger}$ & $7.5 \pm 0.9$ & $7.1 \pm 0.9$ & $6.9 \pm 0.9$ \\
\hline Fasting plasma C-peptide (nmol/liter) & $0.82 \pm 0.06^{\ddagger 1}$ & $0.55 \pm 0.04$ & $0.59 \pm 0.08$ & $0.59 \pm 0.06$ \\
\hline
\end{tabular}

Data are expressed as mean \pm SE. ${ }^{*} P<0.05$ vs nondiabetic twin. ${ }^{\ddagger} P<0.05$ vs controls. ${ }^{\S} P<0.001$ vs controls. ${ }^{\|} P<0.02$ vs NGTTs. ${ }^{9} P$ $<0.001$ vs nondiabetic twins. ${ }^{* *} P<0.01$ vs NGTTs. ${ }^{\ddagger} P<0.01$ vs controls.

The combined group of nondiabetic twins had an elevated glycosylated hemoglobin level compared with the controls, which remained significantly elevated for the IGTT group when considered alone $(n=7)$, but not for the NGTT group $(n=5)$ compared with controls. Fasting plasma insulin and C-peptide concentrations were similar in nondiabetic twins and controls, but were elevated in the NIDDM twins. Blood pressures were similar in all groups: (mmHg; NIDDM twins, $149 \pm 7 / 80 \pm 4$; IGTTs, $144 \pm 11 / 82 \pm 5$; NGTTs, $149 \pm 14 / 81 \pm 6$; controls, $131 \pm 6 / 81 \pm 6$; NS ).

Oral glucose tolerance tests. The nondiabetic twins and controls had similar total insulin areas under the curves during the OGTTs (Fig. 1). However, the incremental insulin area under the curve during the OGTTs was significantly decreased in the NIDDM twins compared with both the nondiabetic twins $(P<0.0005)$ and the controls $(P<0.00005)$ (Fig. 1). The plasma insulin concentration at the time point $30 \mathrm{~min}$ during
OGTTs was significantly lower in the nondiabetic twins compared with controls $(28 \pm 7$ [NGTT], $32 \pm 5$ [IGTT] vs $49 \pm 8$ [controls] $\mu \mathrm{U} / \mathrm{ml}, P<0.02$ ). The 30 -min plasma insulin concentrations were identical in NGTTs and IGTTs. When the groups of NGTTs and IGTTs were considered separately, the decreased 30-min plasma insulin concentration in the NGTTs reached statistical significance $(P<0.05)$ compared with control subjects, whereas this was not the case for the lower 30min plasma insulin concentration in the IGTTs (Fig. 2). The 30-min plasma C-peptide concentrations correlated tightly with the 30-min plasma insulin concentrations $(N=37, \mathrm{R}=0.89$, $P<0.00001)$ and confirmed a delayed secretory response in the nondiabetic twins compared with controls $(1.30 \pm 0.25$ [NGTT], $1.31 \pm 0.12$ [IGTT] vs $1.91 \pm 0.16 \mathrm{nmol} /$ liter, $P$ $<0.005$ ). In addition, the 30 -min plasma C-peptide concentrations were significantly lower compared with controls in both NGTTs $(N=5, P<0.05)$ and IGTTs $(N=7, P<0.02)$

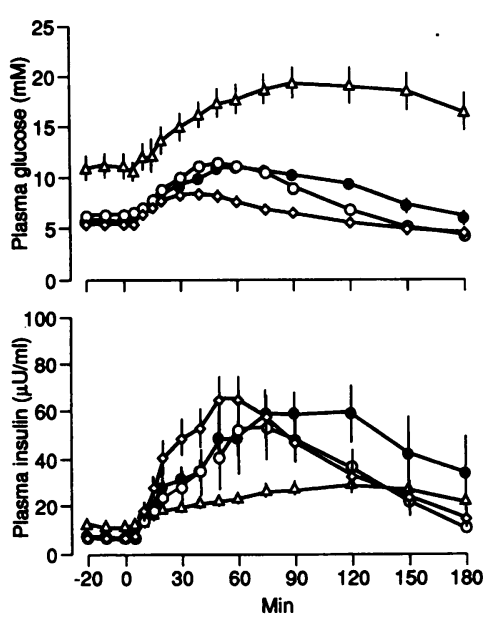

Figure 1. Plasma glucose and insulin concentrations during OGTTs in identical twin pairs discordant for NIDDM and in 13 matched normal control subjects without a family history of diabetes. Open circles, NGTTs with an identical NIDDM co-twin $(N=5)$; closed circles, IGTTs with an identical NIDDM cotwin $(N=7)$; open triangles, identical twins with $\operatorname{NIDDM}(N=12)$, open diamonds, controls $(N$ =13). Data are mean $\pm S E$.

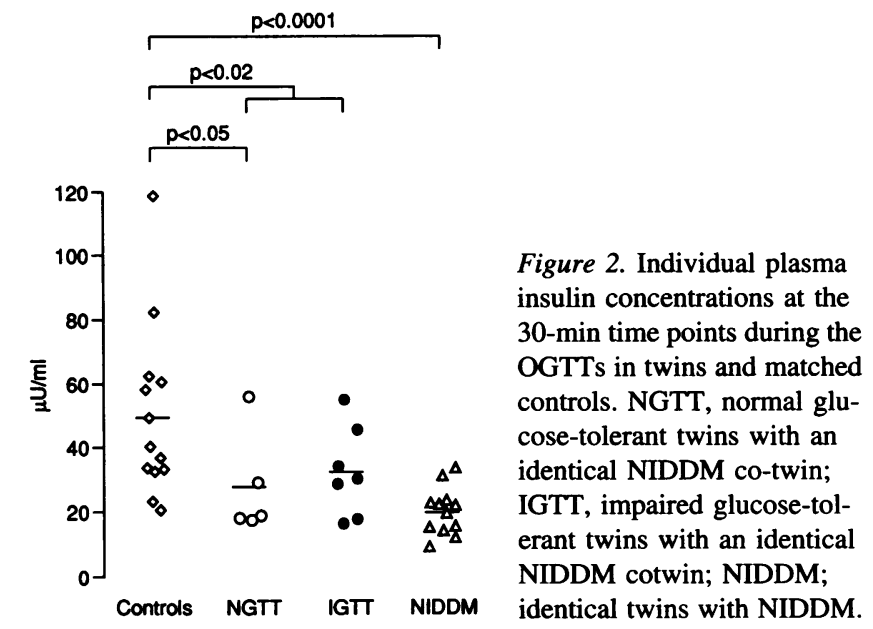

Glucose Metabolism in Twins Discordant for NIDDM 

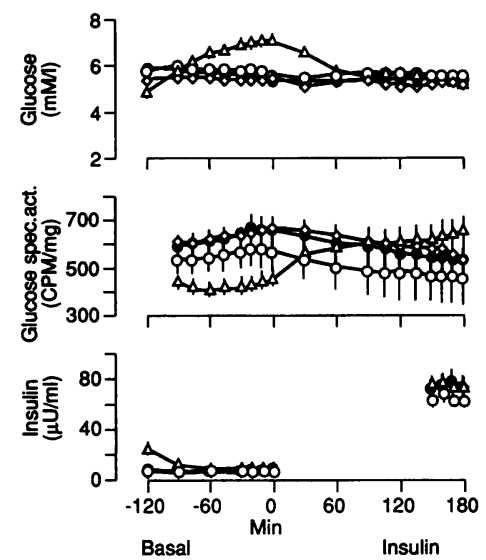

Figure 3. Plasma glucose, glucose specific activities and insulin concentrations in twins and matched controls during studies. Open circles, NGTTs with an identical NIDDM co-twin $(n=5)$; closed circles, IGTTs with an identical NIDDM cotwin; open triangles, identical twins with NIDDM ( $n$ $=12$ ); open diamonds, controls $(n=13)$. Data are mean \pm SE.

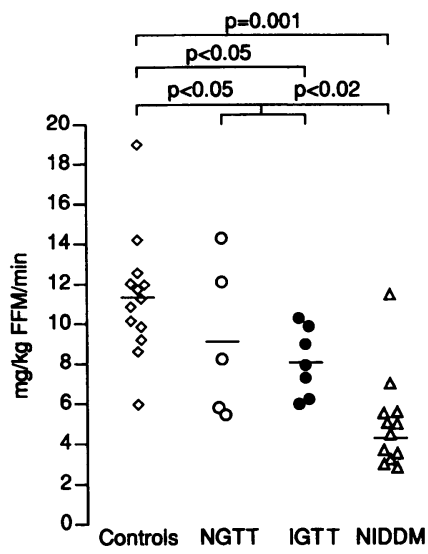

Figure 4. Individual glucose disposal rates during the intravenous insulin infusions (clamp, $40 \mathrm{mU} / \mathrm{m}^{2}$ per min, $180 \mathrm{~min}$ ) in the 12 twin pairs discordant for NIDDM and the 13 matched control subjects. NGTT, normal glucose-tolerant twins with an identical NIDDM co-twin; IGTT, impaired glucose-tolerant twins with an identical NIDDM co-twin; NIDDM, identical twins with NIDDM. when the two groups of nondiabetic twins were tested separately. Finally, the 30-min plasma C-peptide concentrations confirmed a delayed secretory response in the NIDDM twins compared with controls $(1.02 \pm 0.06$ vs $1.91 \pm 0.16 \mathrm{nmol} / \mathrm{liter}, P<$ $0.00005)$, but not compared with their nondiabetic co-twins. $(1.02 \pm 0.06$ vs. $1.30 \pm 0.25$ [NGTT], $1.31 \pm 0.12$ [IGTT], NS.)

Baseline and insulin clamp glucose turnover rates. During the 30-min baseline steady-state period, plasma insulin concentrations were similar in all study groups (Fig. 3). However, because of an increasing plasma glucose concentration in the NIDDM twins after the withdrawal of the prior insulin infusion, the average baseline steady-state plasma glucose concentration was higher in this group compared with both nondiabetic twins $(7.0 \pm 0.2$ vs $5.6 \pm 0.2$ [NGTT], $5.4 \pm 0.2$ [IGTT] $\mathrm{mM}, P$ $<0.0001)$ and controls $(7.0 \pm 0.2$ vs $5.4 \pm 0.1 \mathrm{mM}, P<0.0001)$ (Fig. 3).

Plasma glucose and insulin concentrations were similar during the 30-min insulin-stimulated steady-state periods in all four study groups (Fig. 3). Furthermore, the coefficients of variation of both plasma glucose and insulin concentrations were identical during insulin-stimulated steady-state periods in the different study groups and all were $\leq 5 \%$ for plasma glucose and $\leq 8 \%$ for plasma insulin concentrations.

Baseline HGP rates were similar in the groups of nondiabetic twins and controls $(2.71 \pm 0.28$ [NGTT], $2.62 \pm 0.12$ [IGTT] vs $2.49 \pm 0.13 \mathrm{mg} / \mathrm{kg}$ FFM per min, NS). However, baseline HGP was elevated in the NIDDM twins (3.22 \pm 0.13 $\mathrm{mg} / \mathrm{kg}$ FFM per min) compared with both nondiabetic twins ( $P$ $<0.002)$ and controls $(P<0.0001)$. No statistically significant differences were detected between the rates of HGP in any of the study groups during insulin-stimulated steady-state periods $(0.52 \pm 0.15$ [NIDDM twins] vs $0.11 \pm 0.49$ [NGTT], $0.03 \pm 0.17$ [IGTT] vs $0.17 \pm 0.22$ [controls] $\mathrm{mg} / \mathrm{kg}$ FFM per min, NS).

The combined group of nondiabetic twins had a lower peripheral insulin sensitivity (glucose disposal during hyperinsulinemic clamps) compared with the controls (9.2 \pm 1.7 [NGTT], $8.1 \pm 0.6$ [IGTT] vs $11.4 \pm 0.9 \mathrm{mg} / \mathrm{kg}$ FFM per min, $P<0.05$ ) (Fig. 4). Glucose disposal rates during insulin clamp studies were not statistically significantly different between the NGTTs and IGTTs, but when the NGTTs and IGTTs were tested separately, only the IGTTs had a decreased average insulin-stimulated glucose disposal rate compared with the controls ( $P$ $<0.05$ ) (Fig. 4). Glucose disposal rates during insulin infusion were significantly lower in the NIDDM twins $(5.2 \pm 0.7 \mathrm{mg} / \mathrm{kg}$ FFM per min) compared with both controls and their nondiabetic co-twins (Fig. 4).

Hyperglycemic clamp studies. Plasma glucose concentrations were similar in all four study groups during the experiments (Fig. 5). However, plasma insulin concentrations were clearly higher in the controls without a family history of diabetes during the entire 150-min study period compared with both nondiabetic and NIDDM twins (Fig. 5). Thus, the combined group of nondiabetic twins had a significantly lower first-phase insulin secretion compared with the controls ( $122 \pm 45$ [NGTT], $151 \pm 22$ [IGTT] vs $300 \pm 41 \mu \mathrm{U} / \mathrm{ml} \times \min , P<0.005)$. Furthermore, when the two groups of nondiabetic twins were tested separately, both the decreased response in the NGTTs $(N=5$, $P<0.05)$ and IGTTs $(\mathrm{N}=6, P<0.02)$ reached statistical significance compared with controls (Fig. 6). The first-phase insulin secretion in the NIDDM twins $(-67 \pm 16 \mu \mathrm{U} / \mathrm{ml} \times \min )$ was significantly decreased compared with both controls and their identical nondiabetic co-twins (Fig. 6).

No difference in second-phase insulin response was detected

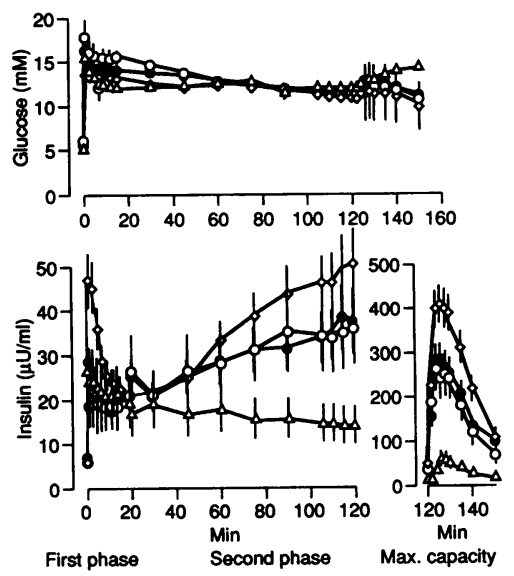

Figure 5. Plasma glucose and insulin concentrations during the 150-min hyperglycemic clamp studies in the twin pairs discordant for NIDDM and matched controls. The plasma glucose concentration was raised acutely from euglycemia by means of an intravenous bolus glucose infusion $(0.27 \mathrm{~g}$ of glucose per $\mathrm{kg}$ of body weight), and maintained constant (clamped) at a concentration of $12 \mathrm{mM}$ for 150 min, using a variable intravenous glucose infusion. Patients with NIDDM received a prior intravenous insulin infusion (withdrawn 30 min before studies), in order to obtain baseline plasma glucose concentrations comparable to those of control subjects prior to and during studies. Open circles, NGTTs with an identical NIDDM co-twin $(n=$ $5)$; closed circles, IGTTs with an identical NIDDM co-twin $(n=6)$; open triangles, identical twins with NIDDM $(n=12)$; open diamonds, controls $(n=13)$. Data are mean \pm SE. 


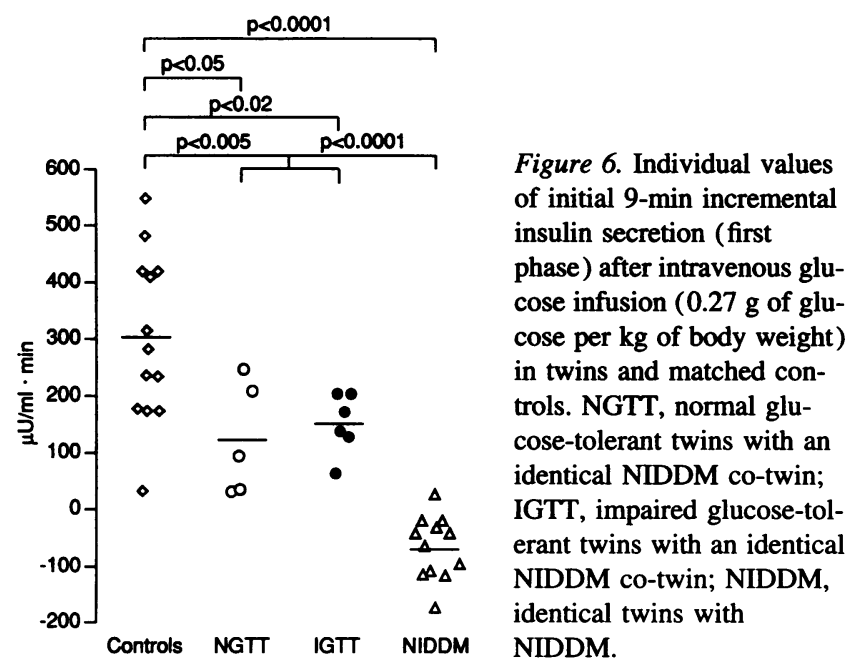

between the combined group of nondiabetic twins (742 \pm 192 [NGTT], 864 \pm 382 [IGTT] $\mu \mathrm{U} / \mathrm{ml} \times \mathrm{min})$ and controls $(773 \pm 274 \mu \mathrm{U} / \mathrm{ml} \times \mathrm{min})$. However, the second-phase insulin response was significantly decreased in the NIDDM twins $(-927 \pm 286 \mu \mathrm{U} / \mathrm{ml} \times \mathrm{min})$ compared with both their nondiabetic cotwins $(P<0.0005)$ and controls $(P<0.0005)$.

The group of nondiabetic twins had a decreased maximal insulin secretory response compared with the controls $(3.39 \pm 0.60$ [NGTT], $3.72 \pm 0.42$ [IGTT] vs $5.69 \pm 0.59 \mathrm{mU} /$ $\mathrm{ml} \times \min , P<0.05)$. This difference did not reach statistical significance for any of the groups of nondiabetic twins when they were tested separately. The maximal insulin secretory response was significantly decreased in the NIDDM twins $(0.44 \pm 0.08 \mathrm{mU} / \mathrm{ml} \times \mathrm{min})$ compared with both their nondiabetic co-twins and controls (Fig. 7).

Relationship between insulin secretion and insulin action. A significant inverse relationship was found between insulinstimulated glucose disposal rates and first-phase insulin secretion in both nondiabetic twins (NGTTs and IGTTs combined, $\mathrm{R}=-0.92, P<0.0001)$ and controls $(\mathrm{R}=-0.70, P<0.01)$ (Fig. 8). Furthermore, an inverse relationship between insulin clamp glucose disposal rates and maximal insulin secretion was also found in both the group of nondiabetic twins $(R=-0.67$, $P<0.02)$ and controls $(\mathrm{R}=-0.54, P<0.05)$ (Fig. 8). However, in the group of NIDDM twins no relationship was

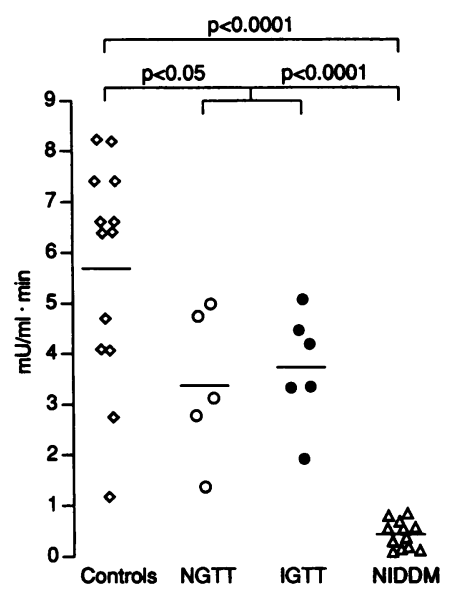

Figure 7. Individual values of insulin secretion (incremental areas under curves) in twins and matched controls during 30-min periods of combined hyperglycemia and intravenous glucogon administration $(1 \mathrm{mg}$ ) (maximal capacity insulin secretion). NGTT, normal glucose-tolerant twins with an identical NIDDM cotwin, IGTT, impaired glucosetolerant twins with an identical NIDDM co-twin, NIDDM, identical twins with NIDDM.

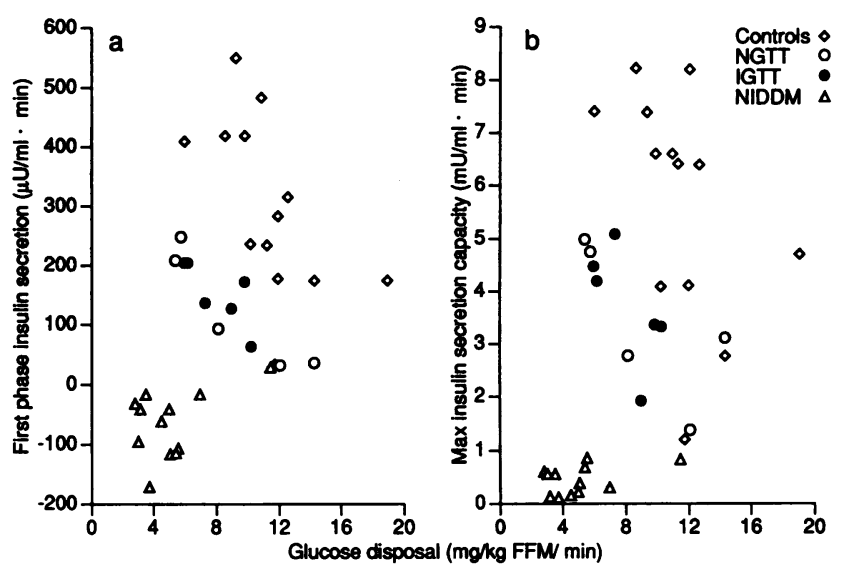

Figure 8. (a) Relationship between glucose disposal rates during clamps and first-phase insulin secretion: controls (open diamonds), $R=-0.70$, $P<0.01$; NGTT (open circles) and IGTT (closed circles), $\mathrm{R}=-0.92$, $P<0.0001$; NIDDM (open triangles), $\mathrm{R}=0.07$, NS). (b) Relationship between glucose disposal rates during clamps and maximal insulin secretion capacity: controls (open diamonds), $\mathrm{R}=-0.54, P<0.05$; NGTT (open circles) and IGTT (closed circles), $\mathrm{R}=-0.67, P<0.02$; NIDDM (open triangles), $\mathrm{R}=0.50, \mathrm{NS}$ ).

found between insulin-stimulated glucose disposal rates and first-phase insulin secretion ( $R=0.07, N S)$ or maximal insulin secretion ( $R=0.50$, NS) (Fig. 8).

Extended statistical data analysis. Parametric ANOVA of data did not identify the parameters age or BMI as statistically significantly independent covariates for any of the individual insulin secretory parameters or glucose turnover rates. In addition, all significant comparisons (findings) made and presented in this study between any of those parameters using nonparametric statistical methods remained statistically significant when corrected for multiple comparisons and for age and BMI as covariates. Finally, multiple regression analyses of data did not identify a relationship between duration of discordance of the individual twin pairs and the degree of $\beta$ cell dysfunction or in vivo insulin action in the group of nondiabetic twins.

\section{Discussion}

The impact of a genetic component for the development of NIDDM is supported by the finding that even the five twins with normal oral glucose tolerance according to the World Health Organization criteria had an elevated fasting plasma glucose concentration and a higher 2-h plasma glucose concentration during the OGTTs compared with the control subjects without any family history of diabetes. Thus, although the apparent concordance rate for diabetes diagnosed after the age of 40 yr according to the initial answers of the questionnaires was surprisingly low (i.e., $23 \%$ ), the study failed to identify completely similar glucose tolerance to that of the control group in the non-diabetic twins with an identical NIDDM co-twin. To this end, it is interesting to note that except for the arbitrarily defined limit for "impaired glucose tolerance" (i.e., $7.8 \mathrm{mM}$ plasma glucose concentration $2 \mathrm{~h}$ after a $75-\mathrm{g}$ oral glucose load), the group of "normal glucose tolerant" twins both quantitatively and qualitatively displayed abnormalities of glucose metabolism very similar to those of IGTTs. Thus, the combined group of nondiabetic twins (NGTTs and IGTTs) were more 
insulin resistant and showed several abnormalities of pancreatic insulin secretion compared with the control individuals without a family history of diabetes.

In contrast to several other recent studies of first-degree relatives to NIDDM patients $(7,9,11,13-16)$, the present study clearly demonstrated the presence of a defective insulin secretion pattern in the nondiabetic (and possibly prediabetic) identical co-twins of NIDDM patients. The insulin secretion defect was expressed phenotypically as a delayed insulin response during OGTTs (Figs. 1 and 2), an impaired first-phase insulin release during intravenous glucose administration (Fig. 6 ), and an impaired insulin release during combined hyperglycemic clamping and intravenous glucagon administration ( maximal insulin secretion capacity; Fig. 7). Furthermore, the study also clearly demonstrated that the secretion of insulin was lower than expected for their degree of insulin resistance (Fig. $8 a$ and $b$ ). Thus, one implication of the present study may be that it adds the possibility for genetically determined defective pancreatic insulin secretion to the list of candidate genes potentially involved in the pathophysiologic events leading to NIDDM. However, formal pedigree linkage studies are required to provide definitive proof for a genetic defect of pancreatic insulin secretion in NIDDM.

The explanation for the difference in insulin secretion data in the nondiabetic twins in this study compared with several other recent studies of genetically predisposed individuals showing either a normal $(10,11)$ or high $(7,9,12-16)$ insulin secretory response deserves further attention. First, a few early studies of first-degree relatives to diabetic patients actually did demonstrate an impairment of insulin release in response to intravenous glucose compared with controls (34-36). Unfortunately, a major limitation of those studies was that the diabetic population was poorly described and may have included relatives with both insulin- and non-insulin-dependent patients. Second, a previous study of five nondiabetic identical twins to NIDDM patients demonstrated a markedly decreased insulin area under the curve during an oral glucose tolerance test (6). This study did not include other measurements of insulin secretion or any measurements of insulin action and HGP in the nondiabetic twins, and no measurements were performed in the NIDDM twins (6). However, this previous finding of a decreased total insulin area under the curve during OGTTs in the nondiabetic twins was not reproduced in this study. Nevertheless, we found a delayed plasma insulin response during the OGTTs and decreased first-phase and maximal insulin secretory responses during hyperglycemic clamping. Thus, our data support the previous conclusion of an impaired insulin secretion in the identical nondiabetic twins of NIDDM patients. Finally, our demonstration of a $\beta$ cell dysfunction in the nondiabetic twins supports and extends the finding by O'Rahilly et al. (37) of an impaired pulsatile insulin secretion in mildly impaired glucosetolerant first-degree relatives of NIDDM patients with a normal first-phase insulin response.

One explanation for the clear finding of impaired insulin secretion in the nondiabetic discordant twins in contrast to other recent studies of first-degree relatives could be that the "NIDDM genotype" is stronger and more purely expressed in identical co-twins of NIDDM patients compared with first-degree relatives, who may only have an average of $50 \%$ genes in common with their NIDDM relatives. However, this is not likely to be the full explanation. Thus, we and others previously found increased fasting and post-glucose (oral and/or intravenous ad- ministered) plasma insulin levels in first-degree relatives with several first- and/or second-degree NIDDM relatives (14) or two NIDDM parents $(9,15,16)$. Another and perhaps more important explanation may be the age of the genetically predisposed nondiabetic individuals, which was clearly higher in the present study (e.g., average age of $64 \mathrm{yr}$ ) compared with other studies. Thus, it is possible that advanced age is an important factor in unmasking the phenotype of a genetically determined impaired insulin secretion pattern. Finally, the possibility exists that the highly selected nondiabetic discordant twins in the present study represent a separate subgroup of the NIDDM population with a distinct genetic defect not necessarily similar to a putative genetic defect in other NIDDM subpopulations (i.e., heterogeneous origin of NIDDM). In this regard, it should be mentioned that islet cell antibodies were not measured in the twins in the present study to exclude the possibility of an immunological component of $\beta$ cell destruction in the twins. However, although the possibility of a distinct genetic defect and/ or of an immunological component of $\beta$ cell destruction in the NIDDM twins cannot be totally excluded, it is worth noting that the NIDDM probands in the present study appeared phenotypically similar to and inseparable from the common NIDDM phenotype, including obesity, onset of diabetes after the age of $40 \mathrm{yr}$, fasting hyperinsulinemia, and acceptable diabetes control for a year long period on treatment with diet and/or oral hypoglycemic agents.

The cross-reactivity with proinsulin in the applied insulin assay of $40 \%$ may obscure a more severe, true insulin secretory defect in some of the twins in the present study. However, the proinsulin cross-reactivity in this study was significantly lower than the proinsulin cross-reactivity of $80 \%$ obtained with the insulin assay used in our previous study of younger relatives of NIDDM patients (14). Thus, the difference in degree of hyperinsulinemia between different "NIDDM relative populations" may also be explained to some extent by different proinsulin cross-reactivities with different insulin assays.

As outlined above, hyperinsulinemia and/or peripheral insulin resistance is a common finding in first-degree relatives of NIDDM patients. In addition, longitudinal studies in American Pima Indians $(38,39)$, in rhesus monkeys $(40)$, and recently in offspring of two diabetic parents $(15,17)$ have demonstrated that insulin resistance precedes the development of frank NIDDM. These consistent findings in several independent population studies have led to the widespread view that genetically determined peripheral insulin resistance may be the primary underlying abnormality of glucose metabolism responsible for the development of NIDDM. Peripheral insulin resistance was also demonstrated in the combined group of nondiabetic identical twins in the present study (Fig. 4), a result that to some extent supports the idea of a genetic component of insulin resistance in NIDDM. On the other hand, the in vivo insulin-stimulated glucose disposal rates in the group of nondiabetic twins markedly overlapped the glucose disposal rates in the control subjects without a family history of diabetes, indicating that peripheral insulin resistance alone may not explain the genetic component of NIDDM. Furthermore, the finding of lower than expected insulin secretion for a given degree of in vivo insulin action in the nondiabetic twins compared with the controls (Fig. $8 a$ and $b$ ) is not directly compatible with any "exhaustion" of the pancreatic insulin secretion due to the peripheral insulin resistance. However, it is important to realize that the finding of defects in both insulin secretion and insulin action in the 
nondiabetic twins does not allow us to determine which of those two defects comes first in the possibly life-long evolutionary process leading to NIDDM in genetically predisposed individuals.

An elevated basal rate of HGP in normoglycemic first-degree relatives of NIDDM patients was previously demonstrated in one study $(18)$, but not confirmed by others $(11,14,16)$ in similar study groups of first-degree relatives. The present study demonstrated a normal basal HGP and a normal insulin suppression of HGP in the group of nondiabetic twins. Therefore, the present study does not provide evidence for a primary or genetic defect per se at the site of hepatic glucose processing. In contrast, the present study clearly indicates that the abnormal hepatic glucose processing in NIDDM during low plasma insulin concentrations is a secondary phenomenon.

Accordingly, a very clear finding in the present study was that all of the defects, including impaired insulin secretion, peripheral insulin resistance, and the disproportionately elevated baseline HGP rate, in frank NIDDM have quantitatively very important secondary (nongenetic) components. It is important to note that the inverse relationship between insulin secretion and peripheral insulin action is conserved in the nondiabetic twins - albeit at a lower level than in controls-while this relationship is lost in the twins with frank NIDDM. Thus, the study strongly supports the notion that frank diabetes develops when the prevailing insulin resistance cannot be compensated for by an increased pancreatic secretion of insulin (1).

As mentioned previously, the present study supports the notion of a genetic component in the etiology (and pathophysiology) of NIDDM. On the other hand, it is also worth noting that the relatively older group of nondiabetic twins - despite their documented 'NIDDM genotype', - have escaped, or postponed, development of frank NIDDM for an average period of at least $9 \mathrm{yr}$ (i.e., the duration of diabetes in their genetically identical co-twins). It may be speculated that this could be due to the fact that members of this group, in contrast to their NIDDM co-twins, have remained nonobese and thereby perhaps have escaped a further impairment of glucose metabolism or insulin secretion due to obesity. If this is the case, the present study strongly indicates a need for primary intervention studies in individuals genetically predisposed to NIDDM (relatives) in order to avoid obesity in those subjects. Interestingly, the secondary component of obesity in the NIDDM twins was apparently not related to increased abdominal obesity (waist/hip ratio), which was similar between the groups of NIDDM patients and their nondiabetic co-twins (Table I). In contrast, the nondiabetic twins had a significantly higher abdominal obesity index (waist/hip ratio) compared with the controls without any family history of diabetes. This indicates that increased abdominal obesity to some extent may work in concert with the genetic component of the disease and may in fact be related to both the peripheral insulin resistance and the pancreatic $\beta$ cell dysfunction in the nondiabetic twins (41).

In conclusion, this study supports a role for a genetic component in the etiology and pathophysiology of NIDDM. An independent and perhaps inherited decreased insulin secretiontogether with decreased insulin sensitivity - may contribute to the development of NIDDM. However, all of the elements in the triumvirate of decreased insulin secretion, peripheral insulin resistance, and elevated HGP in the syndrome of NIDDM also have important secondary (nongenetic) components. Finally, the study indicates a role for obesity in the development of frank NIDDM in genetically predisposed individuals and may indicate a need for primary intervention studies in such groups.

\section{Acknowledgments}

The authors would like to acknowledge the expert technical assistance of Ms K. Dyregaard, Ms H. Vorup, Ms C. Fage Larsen, and Mrs. H. Hansen. Mr. O. Blaabjerg is gratefully acknowledged for the determinations of plasma C-peptide concentrations. Furthermore, we are endebted to Mrs. E. Beck-Nielsen and Mrs. G. Hauge for their great help during the process of tracing and corresponding with all of the twin pairs. We also would like to express our respect and acknowledgements to Professor B. Harvald and to the late Professor M. Hauge for their pioneering work in creating the Danish Twin Registry, which made this study possible. Institute of Forensic Genetics, University of Copenhagen, is acknowledged for the determinations of genetic markers in blood and plasma samples. Dr. Frank Alford is acknowledged for critically reviewing the manuscript. Aage Völund, Ph.D., is acknowledged for statistical assistance.

The study was supported by grants from the Danish Medical Research Council, the Danish Diabetes Association, the NOVO Foundation, the Velux Foundation, and the Clinical Research Institute, Odense University Hospital.

\section{References}

1. Porte, D. 1991. Beta-cells in type 2 diabetes mellitus (Banting Lecture 1990). Diabetes. 40:166-180.

2. Gerich, J. E. 1991. Is muscle the major site of insulin resistance in type 2 (non-insulin-dependent) diabetes mellitus? Diabetologia. 34:607-610.

3. DeFronzo, R. A. 1992. Pathogenesis of type 2 (non-insulin dependent) diabetes mellitus: a balanced overview. Diabetologia. 35:389-397.

4. Barnett, A. H., C. Eff, R. D. G. Leslie, and D. A. Pyke. 1981. Diabetes in identical twins. Diabetologia. 20:87-93.

5. Newman, B., J. V. Selby, M. C. King, C. Slemenda, R. Fabsitz, and G. D. Friedman. 1987. Concordance for type 2 (non-insulin-dependent) diabetes mellitus in male twins. Diabetologia. 30:763-768.

6. Barnett, A. H., A. J. Spiliopoulos, D. A. Pyke, W. A. Stubbs, J. Burrin, and K. G. M. M. Alberti. 1981. Metabolic studies in unaffected co-twins of noninsulin dependent diabetics. Br. Med. J. 282:1656-1658.

7. Leslie, R. D. G., H. P. Volkmann, M. Poncher, I. Hanning, H. Orskov, and K. G. M. M. Alberti. 1986. Metabolic abnormalities in children of non-insulin dependent diabetics. Br. Med. J. 293:840-842.

8. Leslie, R. D. G., A. Ganash, H. P. Volkmann, I. Hanning, and K. G. M. M Alberti. 1988. Insensitivity to insulin in offspring of non-insulin dependent diabetic patients. Diabet. Nutr. Metab. 3:235-237.

9. Haffner, S. M., M. P. Stern, H. P. Hazuda, B. D. Mitchell, and J. K Patterson. 1988. Increased insulin concentrations in nondiabetic offspring of diabetic parents. N. Engl. J. Med. 319:1297-1301.

10. Laws, A., M. L. Stefanick, and G. M. Reaven. 1989. Insulin resistance and hypertriglyceridemia in nondiabetic relatives of patients with noninsulindependent diabetes mellitus. J. Clin. Endocrinol. Metab. 69:343-347.

11. Eriksson, J., A. Franssila Kallunki, A. Ekstrand, C. Saloranta, E. Widen, C. Schalin, and L. Groop. 1989. Early metabolic defects in persons at increased risk for non-insulin-dependent diabetes mellitus. N. Engl. J. Med. 321:337-343.

12. Ho, L. T., Z. Y. Chang, J. T. Wang, S. H. Li, Y. F. Liu, Y. D. Chen, and G. M. Reaven. 1990. Insulin insensitivity in offspring of parents with type 2 diabetes mellitus. Diabet. Med. 7:31-34.

13. Schumacher, M. C., T. M. Maxwell, L. L. Wu, S. C. Hunt, R. R. Williams, and S. C. Elbein. 1992. Dyslipidemias among normoglycemic members of familial NIDDM pedigrees. Diabet. Care 15:1285-1289.

14. Vaag, A., J. E. Henriksen, and H. Beck Nielsen. 1992. Decreased insulin activation of glycogen synthase in skeletal muscles in young nonobese Caucasian first-degree relatives of patients with non-insulin-dependent diabetes mellitus. $J$. Clin. Invest. 89:782-788.

15. Warram, J. H., B. C. Martin, A. S. Krolewski, J. S. Soeldner, and C. R. Kahn. 1990. Slow glucose removal rate and hyperinsulinemia precede the development of type II diabetes in the offspring of diabetic parents. Ann. Intern. Med. 113:909-915.

16. Gulli, G., E. Ferrannini, M. Stern, S. Haffner, and R. A. DeFronzo. 1992. The metabolic profile of NIDDM is fully established in glucose-tolerant offspring of two Mexican-American NIDDM parents. Diabetes. 41:1575-1586.

17. Martin, B. C., J. H. Warram, A. S. Krolewski, R. N. Bergman, J. S. Soeldner, and C. R. Kahn. 1992. Role of glucose and insulin resistance in develop- 
ment of type 2 diabetes mellitus: results of a 25 -year follow-up study. Lancet 340:925-929.

18. Osei, K. 1990. Increased basal glucose production and utilization in nondiabetic first-degree relatives of patients with NIDDM. Diabetes. 39:597-601.

19. Zimmet, P. 1982. Type 2 (non-insulin-dependent) diabetes - an epidemiological overview. Diabetologia. 22:399-411.

20. Yki-Järvinen, H. 1994. Pathogenesis of non-insulin-dependent diabetes mellitus. Lancet. 343:91-95.

21. Hauge, M., B. Harvald, M. Fischer, K. Gotlieb-Jensen, N. Juel-Nielsen, E. Raebild, R. Shapiro, and T. Videbech. 1968. The Danish Twin Register. Acta Genet. Med. Gemellol. 17:315-331.

22. Husby, H., N. V. Holm, A. Gernow, S. G. Thomsen, K. Kock, and H. Gurtler. 1991. Zygosity, placental membranes and Weinberg's rule in a Danish consecutive twin series. Acta Genet. Med. Gemellol. 40:147-152.

23. Mitrakou, A., D. Kelley, M. Mokan, T. Veneman, T. Pangburn, J. Reilly, and J. Gerich. 1992. Role of reduced suppression of glucose production and diminished early insulin release in impaired glucose tolerance. $N$. Engl. J. Med. 326:22-29.

24. McGuire, E. A., J. H. Helderman, J. D. Tobin, R. Andres, and M. Berman. 1976. Effects of arterial versus venous sampling on analysis of glucose kinetics in man. J. Appl. Physiol. 41:565-573.

25. Vaag, A., P. Damsbo, O. Hother Nielsen, and H. Beck Nielsen. 1992. Hyperglycaemia compensates for the defects in insulin-mediated glucose metabolism and in the activation of glycogen synthase in the skeletal muscle of patients with type 2 (non-insulin-dependent) diabetes mellitus. Diabetologia. 35:80-88.

26. DeFronzo, R. A., J. D. Tobin, and R. Andres. 1979. Glucose clamp technique: a method for quantifying insulin secretion and resistance. Am. J. Physiol. 237:E214-E223.

27. Molina, J. M. A. D. Baron, S. V. Edelman, G. Brechtel, P. Wallace, and J. M. Olefsky. 1990. Use of a variable tracer infusion method to determine glucose turnover in humans. Am. J. Physiol. 258:E16-E23.

28. Steele, R. 1959. Influence of glucose loading and of injected insulin on hepatic glucose output. Ann. NY Acad. Sci. 82:420-430.

29. Cowan, J. S., and G. J. Hetenyi. 1971. Glucoregulatory responses in normal and diabetic dogs recorded by a new tracer method. Metabolism. 20:360372.
30. Lukaski, H. C., P. E. Johnson, W. W. Bolonchuk, and G. I. Lykken. 1985. Assessment of fat-free mass using bioelectrical impedance measurements of the human body. Am. J. Clin. Nutr. 41:810-817.

31. Halter, J. B., R. J. Graf, and D. J. Porte. 1979. Potentiation of insulin secretory responses by plasma glucose levels in man: evidence that hyperglycemia in diabetes compensates for impaired glucose potentiation. J. Clin. Endocrinol. Metab. 48:946-954.

32. Hemmilä, I., S. Dakubu, V.-M. Mukkala, H. Siitari, and T. Lövgren. 1984. Europium as a label in time-resolved immunofluorometric assays. Anal. Biochem. 137:335-343.

33. Hother-Nielsen, O., and H. Beck-Nielsen. 1990. On the determination of basal glucose production rate in type 2 (non-insulin dependent) diabetes using primed-continuous 3- ${ }^{3} \mathrm{H}$-glucose infusion. Diabetologia. 33:603-610.

34. Cerasi, E., and R. Luft. 1963. Plasma insulin response to hyperglycemia induced by glucose infusion in human subjects. Lancet. ii:1359-1361.

35. Colwell, J. A., and A. Lein. 1967. Diminished insulin response to hyperglycemia in prediabetes and diabetes. Diabetes. 16:560-565.

36. Soeldner, J. S., R. E. Gleason, R. F. Williams, M. J. Garcia, D. M. Beardwood, and A. Marble. 1968. Diminished serum insulin response to glucose in genetic prediabetic males with normal glucose tolerance. Diabetes. 17:17-26.

37. O'Rahilly, S., R. C. Turner, and D. R. Matthews. 1988. Impaired pulsatile secretion of insulin in relatives of patients with non-insulin-dependent diabetes. N. Engl. J. Med. 318:1225-1230.

38. Lillioja, S., D. M. Mott, B. V. Howard, P. H. Bennett, H. Yki Jarvinen, D. Freymond, B. L. Nyomba, F. Zurlo, B. Swinburn, and C. Bogardus. 1988. Impaired glucose tolerance as a disorder of insulin action. Longitudinal and crosssectional studies in Pima Indians. N. Engl. J. Med. 318:1217-1225.

39. Lillioja, S., D. M. Mott, M. Spraul, R. Ferraro, J. E. Foley, E. Ravussin, W. C. Knowler, P. H. Bennett, and C. Bogardus. 1993. Insulin resistance and insulin secretory dysfunction as precursors of non-insulin-dependent diabetes mellitus. N. Engl. J. Med. 329:1988-1992.

40. Bodkin, N. L., B. L. Metzger, and B. C. Hansen. 1989. Hepatic glucose production and insulin sensitivity preceding diabetes in monkeys. Am. J. Physiol. 256:E676-E681.

41. Peiris, A. N., J. I. Stanger, R. L. Vogel, A. Nakagawa, and E. Samols. 1992. Body fat distribution and peripheral insulin sensitivity in healthy men: role of insulin pulsatility. J. Clin. Endocrinol. Metab. 75:290-294. 